\title{
Comparison of neonatal outcome parameters between thick and thin meconium stained liquor: a prospective study
}

\author{
Rupa Vani K. ${ }^{1}$, Banishree Pati ${ }^{1 *}$, Veena K. S. ${ }^{2}$, Hemanth Kumar V. R. ${ }^{3}$
}

\begin{abstract}
${ }^{1}$ Department of Obstetrics and Gynecology, Indira Gandhi Medical College and Research Institute, Pondicherry, India ${ }^{2}$ Department of Obstetrics and Gynecology, Sri Manakula Vinayagar Medical College, Pondicherry, India ${ }^{3}$ Department of Anaesthesiology, Mahatma Gandhi Medical College, Pondicherry, India
\end{abstract}

Received: 15 October 2018

Accepted: 20 October 2018

\author{
*Correspondence: \\ Dr. Banishree Pati, \\ E-mail: drbani1807@gmail.com
}

Copyright: (c) the author(s), publisher and licensee Medip Academy. This is an open-access article distributed under the terms of the Creative Commons Attribution Non-Commercial License, which permits unrestricted non-commercial use, distribution, and reproduction in any medium, provided the original work is properly cited.

\begin{abstract}
Background: Meconium stained liquor is a commonly observed phenomenon in the day-to-day obstetric practice, the incidence being $12-22 \%$. Meconium stained liquor can be considered as a normal physiological event in a term fetus in the absence of fetal heart rate abnormalities. It has greater significance as one of the parameters of fetal distress, when associated with abnormal fetal heart rate pattern. The aim of the present study was to study the association of, fetal heart rate abnormalities, mode of delivery and neonatal outcome with different grades of meconium stained liquor.

Methods: A prospective study was conducted in one hundred and fifty cases of meconium stained liquor beyond 37 weeks gestation admitted to the labor room in a tertiary care Centre. Depending on the consistency of meconium, the patients were divided into two groups namely, Thick meconium stained liquor (group K) and Thin meconium stained liquor (group N). Maternal conditions, Intrapartum fetal heart rate pattern, Apgar scores and neonatal morbidities were studied in relation to the grade of meconium. The proportions between the two groups were compared using chisquare test and Fisher's exact t-test.

Results: The incidence of post term pregnancy $(p=0.004)$, unbooked $(p=0.007)$ status and oligohydramnios $(p=0.01)$ were significantly higher among group $\mathrm{K}$ when compared to group $\mathrm{N}$. Non-reassuring fetal heart rate pattern $(\mathrm{p}=0.002)$ and Apgar score $\leq 7(\mathrm{p}=0.02)$ were significantly higher in group $\mathrm{K}$. In group $\mathrm{K}$, non-reassuring fetal heart rate pattern and reduced beat to beat variability were significantly associated with low Apgar score $(\mathrm{p}=0.01)$.

Conclusions: Neonatal outcomes like low Apgar score, meconium aspiration syndrome are strongly associated with thick meconium stained liquor. Visual grading of liquor into thick and thin meconium stained may help in timely obstetric intervention leading to a better neonatal outcome.
\end{abstract}

Keywords: Apgar score, Cardiotocography, Neonatal outcome, Thick meconium stained liquor

\section{INTRODUCTION}

The journey through the birth canal is the first and probably, the most hazardous journey a person undergoes. It is the responsibility of the obstetrician to act as a carrying guide for the fetus to make the journey safe. Meconium stained liquor is a commonly observed phenomenon in the day-to-day obstetric practice, the incidence being $12-22 \% .^{1}$ At one end of the spectrum, meconium passage is a normal physiological event in a term fetus and is not a sign of fetal distress in the absence of fetal heart rate abnormalities. ${ }^{2,3}$ At the other end, meconium is one of the parameters of fetal distress, and when associated with signs of fetal asphyxia, it has greater significance. ${ }^{4}$

Though scalp blood $\mathrm{pH}$ estimation is a superior and sensitive method in diagnosing fetal hypoxia, it is not 
available to even small fraction of patients delivered in our country. So, it is necessary to correlate intrapartum fetal heart rate pattern, Apgar score and neonatal outcome in meconium stained liquor in diagnosing fetal hypoxia. ${ }^{5}$ The meconium stained liquor and its associations are important determinants of maternal and perinatal morbidity and mortality. ${ }^{6}$

The presence of meconium stained liquor diagnosed by clinical visual inspection and can be graded into thin and thick meconium. ${ }^{7,8}$ Though association of meconium with fetal outcome is well researched, the relation of different grades of meconium stained liquor with fetal outcome is not well studied. The present study, various maternal factors associated with meconium staining, fetal heart rate abnormalities, mode of delivery and neonatal outcome have been evaluated in relation to different degrees of meconium staining.

\section{METHODS}

After ethical clearance from institute Ethics committee one hundred and fifty consecutive cases of meconium stained liquor beyond 37 weeks gestation admitted to the labor room in a tertiary care center were enrolled for the study.

Patients with malpresentation, multiple pregnancies and congenital anomalies were excluded from the study. After rupture of membrane either spontaneous or artificial, the liquor was visually inspected.

Depending on the grade of meconium stained liquor, the patients were divided into two groups namely, group $\mathrm{K}$ (thick meconium stained liquor) and group $\mathrm{N}$ (thin meconium stained liquor).

The group $\mathrm{K}$ represents patients where the meconium was thick undiluted, dark green in color (pea soup type) and group $\mathrm{N}$ represents patients where the meconium was thin, diluted light green in color. Routine hematological and urine examination was done.

Ultrasound was done to rule out congenital malformations and to assess the amniotic fluid. Intrapartum cardiotocography was done for all cases and fetal heart rate pattern was noted.

Fetal heart rate abnormalities were classified and documented as per NICE clinical guidelines on intrapartum care 2007. ${ }^{9}$ History of any complications during present pregnancy was noted. General physical examination and obstetric examination were performed. Gestational age by virtue of history and examination was recorded.

The mode of delivery and fetal outcomes were noted in each group. Neonatal details considered were Apgar score of the baby at $5 \mathrm{~min}$, need for resuscitative measures, birth weight, NICU admission.
Fetal heart rate pattern was correlated with the Apgar scores. The neonates admitted to NICU were followed up. Neonatal morbidity and mortality were noted.

\section{Statistical analysis}

The quantitative variables were analyzed and the significance of the difference in the means between the two groups was tested with t-independent test. As for the qualitative variables, the significance of their occurrence in the two groups were compared in terms of proportions. The proportions between the two groups were compared using chi-square test and Fisher's exact t-test.

Descriptive analysis was also included in the study as frequencies and percentages wherever it is necessary. In all comparisons, a P-value of $<0.05$ was considered to be statistically significant.

\section{RESULTS}

A total of 150 expectant mothers who were in labor and presented with meconium stained liquor were recruited for the study. They were followed up to their delivery and their neonates were followed up until their hospital stay. The number of cases in Group K were 70 (46.67\%) and in Group N were 80 (53.33\%).

The mean age among the group $\mathrm{K}$ was 22.77 years and that among the group $\mathrm{N}$ was 23.93 years. Comparisons of different variables were made between these two groups.

Table 1 shows various factors associated with meconium stained liquor. The incidence of postterm pregnancy (Gestational age $>42$ weeks) (chi square $=8.24, p=0.004$ ), unbooked status (Chi square $=11.3, \mathrm{p}=0.007$ ) and oligohydramnios (chi square $=6.35, \mathrm{p}=0.01$ ) were significantly higher among group $\mathrm{K}$ when compared to group $\mathrm{N}$.

Table 1: Factors associated with meconium staining.

\begin{tabular}{|llll|}
\hline Factors & $\begin{array}{l}\text { Group K } \\
(\mathbf{N}=70) \mathbf{N} \\
(\%)\end{array}$ & $\begin{array}{l}\text { Group N } \\
(\mathbf{N}=80) \mathbf{N} \\
(\%)\end{array}$ & $\begin{array}{l}\text { P } \\
\text { value }\end{array}$ \\
\hline $\begin{array}{l}\text { Gestational age }> \\
\text { 42 weeks }\end{array}$ & $11(15.7)$ & $2(2.5)$ & 0.004 \\
\hline Unbooked status & $31(44.2)$ & $15(18.7)$ & 0.007 \\
\hline Oligohydramnios & $9(12.8)$ & $1(1.2)$ & 0.01 \\
\hline Anaemia & $7(10.0)$ & $4(5.0)$ & $>0.05$ \\
\hline Diabetes & $1(1.4)$ & $0(0.00)$ & $>0.05$ \\
\hline Preeclampsia & $4(5.7)$ & $7(8.7)$ & $>0.05$ \\
\hline Rh -ve & $0(0.00)$ & $1(1.2)$ & $>0.05$ \\
\hline Induced Labour & $17(24.2)$ & $19(23.7)$ & $>0.05$ \\
\hline
\end{tabular}

There was no association between the medical conditions like anemia, diabetes, preeclampsia, $\mathrm{Rh}$ factor (negative) and the type of meconium stained liquor $(\mathrm{p}>0.05)$. The proportion of cases among whom the labor was induced 
did not differ significantly between the two groups ( $p>0.05)$ which may suggest that induction of labor did not increase the thickness of meconium stained liquor.

It may be seen from fig 1, that the proportion of cases who underwent LSCS was significantly higher (chi square $=9.42$, $\mathrm{p}=0.001$ ) among group $\mathrm{K}$ when compared to that in group $\mathrm{N}$.

The most common indication for cesarean section was fetal distress in both the groups. However, there was no significant difference $(p>0.05)$ with regard to the indication for cesarean section between the two groups (Table 2).

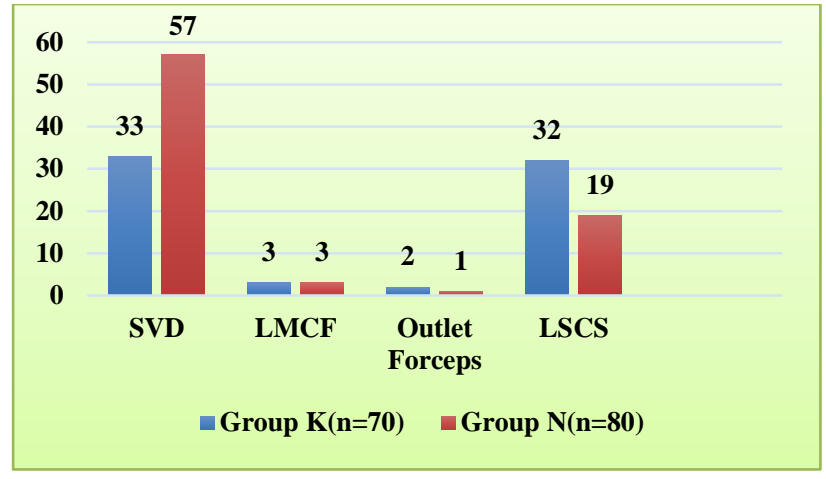

Figure 1: Mode of delivery.

Table 2 Indications for caesarean section.

\begin{tabular}{llll} 
Indication & Group $\mathrm{K}(\mathbf{N}=70) \mathbf{N}(\%)$ & Group N $(\mathbf{N}=80) \mathbf{N}(\%)$ & Total \\
\hline Foetal distress & $15(46.88)$ & $6(31.59)$ & $21(41.18)$ \\
\hline CPD & $5(15.63)$ & $5(26.32)$ & $10(19.16)$ \\
\hline Precious pregnancy & $1(3.13)$ & $3(15.79)$ & $4(7.84)$ \\
Non-progress of labour & $5(15.63)$ & $2(10.52)$ & $1(13.73)$ \\
\hline Deep transverse arrest & 0 & $1(5.26)$ & $2(3.92)$ \\
\hline Obstructed labour & $2(6.25)$ & 0 & $3(5.88)$ \\
Failed induction & $2(6.25)$ & $1(5.26)$ & $2(3.92)$ \\
\hline Oligohydramnios & $2(6.25)$ & 0 & $1(1.96)$
\end{tabular}

The proportion of cases having non-reassuring fetal heart rate pattern was significantly higher in group $\mathrm{K}$ (chi square=9.24; $\mathrm{p}=0.002$ ) (Figure 2 and 3 ).

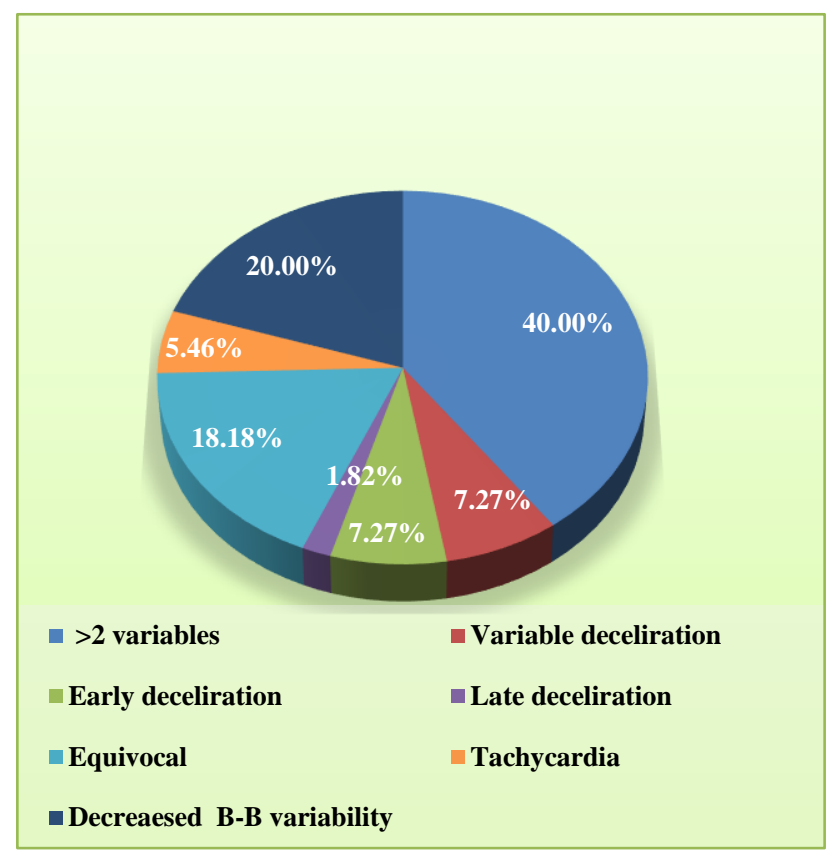

Figure 2: Non-reassuring foetal heart rate pattern in Group K.

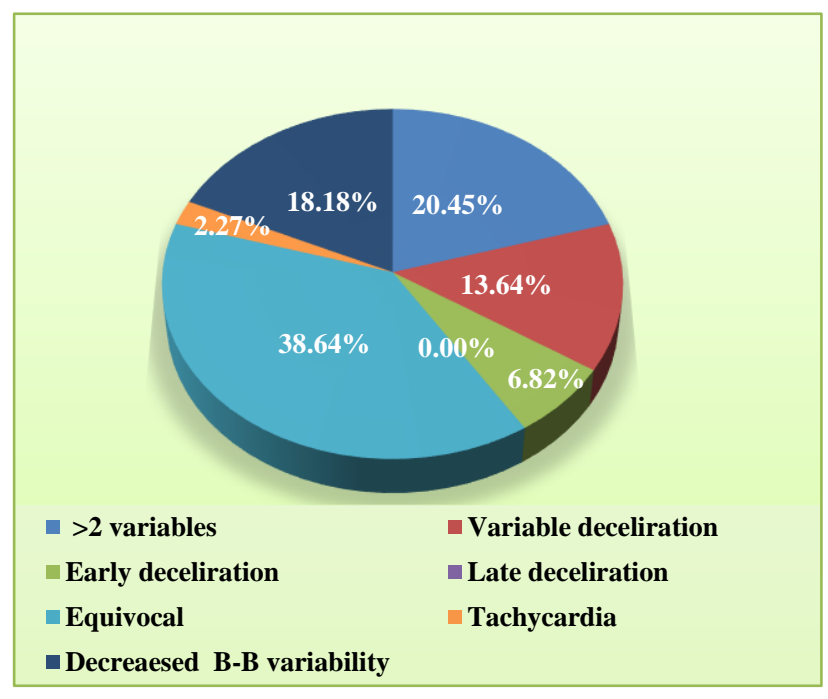

Figure 3: Non-reassuring foetal heart rate pattern in Group N.

The proportion of cases with Apgar score $\leq 7$ was also significantly higher in group $\mathrm{K}$ when compared to group $\mathrm{N}$ (chi square $=5.75, \mathrm{p}$ value $=0.02)($ Table 3$)$.

In group $\mathrm{K}$, non-reassuring FHR pattern was significantly associated with Apgar score $\leq 7$ (Chi square $=4.52$; p value $=0.03)$ (Table 4). Similarly, beat-beat variability of 
$<5$, was significantly associated with Apgar score $\leq 7$ (chi square $=6.91 ; \mathrm{p}=0.01)$. In group $\mathrm{N}$, fetal heart rate pattern and beat to beat variability was not associated with Apgar score $(\mathrm{P}>0.05)$ (Table 4).

Table 3 Foetal and neonatal outcome.

\begin{tabular}{|c|c|c|c|c|}
\hline Parameters & & Group $K(N=80) \mathbf{N}(\%)$ & Group $\mathbf{N}(\mathbf{N}=80) \mathbf{N}(\%)$ & p value \\
\hline \multirow{2}{*}{ Fetal heart pattern } & Reassuring & $15(21.43)$ & $36(45.00)$ & \multirow{2}{*}{0.002} \\
\hline & Nonreassuring & $55(78.57)$ & $44(55.00)$ & \\
\hline \multirow{2}{*}{ APGAR score $5 \mathrm{~min}$} & $\leq 7$ & $23(31.42)$ & $12(15)$ & \multirow{2}{*}{0.02} \\
\hline & $>7$ & $48(6858)$ & $68(85)$ & \\
\hline Mean birth weight in $\mathrm{kg}$ & & 2.88 & 2.94 & $>0.05$ \\
\hline \multirow{3}{*}{ Neonatal morbidity } & MAS & $11(15.72)$ & $3(3.75)$ & 0.03 \\
\hline & RDS & $10(14.28)$ & $5(6.25)$ & $>0.05$ \\
\hline & NEC & 0 & $1(1.25)$ & $>0.05$ \\
\hline \multirow{3}{*}{$\begin{array}{l}\text { NICU stay } \\
\text { (No. of days) }\end{array}$} & $\leq 2$ & $13(18.57)$ & $3(3.75)$ & \multirow{3}{*}{$>0.05$} \\
\hline & $3-6$ & $5(7.14)$ & $8(10.00)$ & \\
\hline & $\geq 7$ & $2(2.86)$ & $0(0.0)$ & \\
\hline Need for resuscitation & & $33(47.14)$ & $17(21.25)$ & 0.001 \\
\hline \multirow{2}{*}{ Neonatal mortality } & Still birth & $1(1.43)$ & 0 & \multirow{2}{*}{$>0.05$} \\
\hline & Neonatal death & $5(7.34)$ & $3(3.75)$ & \\
\hline
\end{tabular}

Table 4 Association of 5 min. Apgar score with foetal heart rate pattern and beat to beat variability.

\begin{tabular}{|c|c|c|c|c|c|}
\hline \multirow{2}{*}{\multicolumn{2}{|c|}{ Parameters Studied }} & \multicolumn{2}{|l|}{ Group K } & \multicolumn{2}{|l|}{ Group N } \\
\hline & & Apgar $\leq 7(n=23)$ & Apgar $>7(n=47)$ & Apgar $\leq 7(n=12)$ & Apgar $>7(n=68)$ \\
\hline \multirow{2}{*}{$\begin{array}{l}\text { Foetal heart rate } \\
\text { pattern }\end{array}$} & Reassuring & $1(4.35)$ & $14(29.79)$ & $3(25.00)$ & $33(48.53)$ \\
\hline & Non-reassuring & $22(95.65)$ & $33(70.21)$ & $9(75.00)$ & $35(51.47)$ \\
\hline \multirow{2}{*}{ B-B variability } & $<5$ & $16(69.57)$ & $17(36.17)$ & $5(41.67)$ & $15(22.06)$ \\
\hline & May-25 & $7(30.43)$ & $30(63.83)$ & $7(58.33)$ & $53(77.94)$ \\
\hline
\end{tabular}

Neonatal morbidity was significantly higher $(30 \%)$ in group $\mathrm{K}$ when compared to that in group $\mathrm{N}(11.25 \%)$ (chi square $=8.20 ; \mathrm{p}$ value $=0.004)$. Meconium aspiration syndrome (MAS) was significantly high in group K (Chi square $=3.95, \mathrm{p}=0.03$ ) when compared to the group $\mathrm{N}$. However, the proportion of cases presenting with respiratory distress syndrome (RDS), necrotizing enterocolitis (NEC) and septicemia did not vary between the two groups. The duration of stay in NICU $(p>0.05)$ also did not vary significantly with the type of meconium stained liquor. The proportion of cases which needed resuscitation was significantly higher among group $\mathrm{K}$ when compared to the same with group $\mathrm{N}$ (Chi square $=11.3, \mathrm{p}$ value $=0.001)$. There was one still birth in group $\mathrm{K}$ and no difference in the proportion of neonatal mortality among the two groups $(\mathrm{p}>0.05)$ (Table 3$)$.

\section{DISCUSSION}

The incidence of thick meconium was significantly higher in patients with post term pregnancy $(15.71 \%$ vs $2.5 \% \mathrm{p}=0.004)$, oligohydramnios $(12.8 \%$ vs $1.2 \%$, $\mathrm{p}=0.01)$ and in unbooked cases $(44.2 \%$ vs $18.7 \%$, $\mathrm{p}=0.007$. Similar findings were seen in the studies done by Wong et al, Sheiner et al and Yinka Oyelese et al. ${ }^{10-12}$ The increased incidence of meconium staining in oligohydramnios may be the result of intrapartum fetal distress as a consequence of cord compression. It is also likely that meconium released into an already reduced amniotic fluid volume causes thick, viscous meconium staining. The increased likelihood of oligohydramnios in post term pregnancies explains the increased thickness of meconium in postterm pregnancy. However, the incidence of postterm pregnancy in present study $(8.67 \%)$ was significantly low when compared to the study done by Pushpa Bhatia et al (32.4\%). The reason could be due to the fact that most of the pregnancies which are booked in the hospital are terminated before 42 weeks. Authors did not find any significant relation of diabetes mellitus, $\mathrm{Rh}$-ve pregnancy, preeclampsia or anaemia with thick meconium stained liquor. ${ }^{13}$

In present study, no significant relation was found between induction of labor with the grades of meconium staining. There was relatively higher incidence of cesarean section in group $\mathrm{K}$ when compared to Group $\mathrm{N}$ $(45.71 \%$ vs $23.75 \% \quad \mathrm{p}=0.02)$. The most common indication being fetal distress (46.88\% vs $31.58 \%)$. Similarly, in the study done by Desai DS et al and Patil Kamal et al, the incidence of cesarean section was high in group $\mathrm{K}(56.2 \%$ vs $18 \%) \cdot{ }^{14,15}$ The most common indication for cesarean section in their study was also 
fetal distress. The probable reason for this could be the great importance assumed by the meconium in many medico legal pursuits and also the unavailability of fetal scalp $\mathrm{pH}$ monitoring for further confirmation of fetal distress.

In present study, a significantly higher proportion of the fetuses showed non-reassuring fetal heart rate pattern (78.57\% vs $55 \% \mathrm{p}=0.002)$, low $5 \mathrm{~min}$ Apgar score (31.42\% vs $15 \%$ ) in group $\mathrm{K}$ when compared to group $\mathrm{N}$. Similar findings were seen in the study done by Starks GC et al and Desai DS et al. As thick meconium is particulate, when aspirated, it significantly increases fetal hypoxia which is reflected as non- reassuring fetal heart rate pattern. ${ }^{5,14}$

The average birth weight in present study was $2.88 \mathrm{~kg}$ in group $\mathrm{K}$ and $2.94 \mathrm{~kg}$ in group $\mathrm{N}$. Whereas in the study done by Yinka et al $(3.43 \mathrm{~kg})$, the average birth weight was significantly higher compared to present study. This could be due to low average birth weight in Indian population compared to western countries. ${ }^{12}$

Neonatal morbidity was significantly high in group $\mathrm{K}$ in present study. Though there was no significant difference in the incidence of Respiratory distress syndrome(RDS) (12.5\% vs $8.75 \% \mathrm{p}>0.05)$ among the two groups, the incidence of MAS $(13.75 \%$ vs $4.29 \% \mathrm{p}=0.046)$ was significantly high in group $\mathrm{K}$ compared $\mathrm{t}$ group $\mathrm{N}$. Similar finding was noted in the study done by Rossi et al who found an incidence of MAS of $9.2 \%, 73 \%$ of them being thick meconium stained liquor. ${ }^{16}$

Meconium aspiration syndrome (MAS) is a disorder resulting from peripartum inhalation of meconium stained liquor leading to chemical pneumonitis with inflammation of pulmonary tissues, mechanical obstruction of airways and hypoxia. When thin meconium staining occurs, aspiration before labor is readily cleared from the lungs by normal physiological mechanism in normal healthy fetuses. But this process is impaired when the meconium remains thick and undiluted. This explains the reason for higher incidence of meconium aspiration syndrome in thick meconium stained liquor.

Though the incidence of low 5 min Apgar scores were significantly high in group K $(31.42 \%)$ in present study compared to group $\mathrm{N}(15 \%)$, when the fetal heart rate tracing was reassuring and beat-beat variability $>5$ per min, the proportion of babies which had 5 min Apgar score $>7$ was significantly high.

In group $\mathrm{N}$, though 33 babies out of the 36 who had reassuring pattern had 5 min Apgar score $>7$, there was no statistically significant correlation between the $5 \mathrm{~min}$ Apgar score and reassuring fetal heart rate pattern in present study. Similarly, there was also no significant correlation between beat-beat variability and 5 min Apgar score in group N. The probable reason could be the small number of patients included in present study. The study done by Gregory C Starks and Rossi et al also showed significant association between thick meconium, nonreassuring fetal heart rate pattern and low 5 min Apgar score. ${ }^{5,16}$ A review done by Suresh Babu $\mathrm{N}$ et al also showed that in the absence of fetal heart rate abnormalities, the presence of meconium does not indicate fetal compromise. ${ }^{17}$

There were 9 perinatal deaths in present study (6\%) out of which $6(66.67 \%)$ occurred in group $\mathrm{K}$ and $3(33.33 \%)$ occurred in group N. Four of the deaths in group $\mathrm{K}$ were due to MAS whereas none were due to meconium aspiration syndrome in group N. All the babies had nonreassuring fetal heart rate pattern and decreased beat-beat variability. Three of the babies which had severe birth asphyxia showed bradycardia. The incidence of perinatal deaths in the study done by Pushpa Bhatia et al was $9.2 \%, 25.35 \%$ of them being due to meconium aspiration syndrome. ${ }^{12}$ In the study done by Gupta et al all perinatal deaths occurred in Thick meconium group only and were associated with severe birth asphyxia. In the study done by Alchalabi et al, $15.8 \%$ of the deaths were due to meconium aspiration syndrome. ${ }^{18,19}$

\section{CONCLUSION}

Maternal conditions like post term pregnancy oligohydramnious and unbooked status are associated with high incidence of thick meconium stained liquor. Thick meconium stained liquor is highly associated with non-reassuring fetal heart rate pattern and high incidence of caesarean section. Neonatal outcomes like low Apgar score, meconium aspiration syndrome are strongly associated with thick meconium stained liquor. Visual grading of liquor into thick and thin meconium stained may help in timely obstetric intervention leading to better neonatal outcome. Further studies needed to establish the grading of meconium stained liquor.

Funding: No funding sources

Conflict of interest: None declared

Ethical approval: The study was approved by the Institutional Ethics Committee

\section{REFERENCES}

1. Gary F Cunningham, Kenneth J Leveno, Steven L Bloom, John c Hauth, Larry GillstrapIII, Katharine D Wenstrom Williams Obstetrics,22nd ed. New York: Mc Graw Hill; 2005.

2. Fenton AN. Steer CM. Meconium in utero, a sign of fetal maturity. Am.J. Obstet Gynaecol. 1962;83:354.

3. Katz LV. Bowes WA. Meconium aspiration syndrome, reflection on a musky subject. Am. J.Obstet Gynaecol. 1992;166(1):171-83.

4. Ramin KD, Leveno KJ, Kelly MS, Carmody TJ. Amniotic fluid meconium: A fetal environmental hazard. Obst Gynecol. 1996;87(2):181-4. 
5. Starks GC. Correlation of meconium-stained amniotic fluid, early intrapartum fetal $\mathrm{pH}$, and Apgar scores as predictors of perinatal outcome. Obstet Gynecol. 1980; 56(5):604-9.

6. Kumari R, Srichand P, Saha SZ, Devrajani BR. Fetal outcome in patients with meconium stained liquor. J Pak Med Assoc. 2012;62(5):474-6.

7. Davis RO, Philips JB III, Haris BA Jr, Wilson ER, Huddleston JF. Fetal meconium aspiration syndrome occurring despite airway management considered appropriate. Am J Obstet Gynecol. 1985;151(6):7316.

8. Lenovo KJ, Quirk JG Jr, Cunningham FG, Nelson SD, Santos-Ramos R, Toofanian A, et al. Prolonged pregnancy. 1. Observations concerning the causes of fetal distress. Am J Obstet Gynecol 1984;150(5):465-73.

9. Intrapartum Care NICE Clinical Guideline 55 September 2007.

10. Wong SF, Chow KM, Ho LC. The relative risk of 'fetal distress' in pregnancy associated with meconium-stained liquor at different gestation. J Obstet Gynaecol. 2002;22(6):594-9.

11. Sheiner E, Hadar A, Shoham-Vardi I, Hallak M, Katz M, Mazor M. The effect of meconium on perinatal outcome: a prospective analysis. J Matern Fetal Neonatal Med.2002;11(1):54-9.

12. Oyelese Y, Culin A, Ananth CV, Kaminsky LM, Vintzileos A, Smulian JC. Meconium-stained amniotic fluid across gestation and neonatal acidbase status. Obstet Gynecol. 2006;108(2):345-9.

13. Pushpa Bhatia, Neelam Ela. Fetal and neonatal outcome of babies in meconium stained amniotic fluid and meconium aspiration syndrome. J Obstet Gynaecol India. 2007;57(6):501-4.
14. Desai D, Maitra N, Patel P. Fetal heart rate patterns in patients with thick meconium staining of amniotic fluid and its association with perinatal outcome. Int $\mathbf{J}$ Reprod Contracept Obstet Gynecol. 2017;6(3):10305.

15. Patil Kamal P, Swami MK, Samatha K. A one-year cross sectional study of management practices of meconium stained amniotic fluid and perinatal outcome. J Obstet Gynaecol India. 2006;56(2):12830.

16. Rossi EM, Philipson EH, Williams TG, Kalhan SC. Meconium aspiration syndrome: intrapartum and neonatal attributes. Am J Obstet Gynecol. 1989; 161(5):1106-10.

17. Ahanya SN, Lakshmanan J, Morgan BL, Ross MG. Meconium passage in utero: mechanisms, consequences and management. Obstet Gynecol Surv. 2005;60(1):45-56.

18. Gupta V, Bhatia BD, Mishra OP. Meconium stained amniotic fluid: antenatal, intrapartum and neonatal attributes. Indian Pediatr. 1996;33(4):293-7.

19. Alchalabi H, Abu-Heija AT, El-Sunna E, Zayed F, Badria LF, Obeidat A. Meconium-stained amniotic fluid in term pregnancies-a clinical view. J Obstet Gynaecol. 1999;19(3):262-4.

Cite this article as: Vani RK, Pati B, Veena KS, Kumar HVR. Comparison of neonatal outcome parameters between thick and thin meconium stained liquor: a prospective study. Int J Reprod Contracept Obstet Gynecol 2018;7:4407-12. 